\title{
HEDGE COM COMBINAÇÃO DE ATIVIDADES AGROPECUÁRIAS
}

\author{
Karine Diniz Xavier* \\ Kellen Cristina Campos Fernandes** \\ Reginaldo Santana Figueiredo*** \\ Odilon José de Oliveira Neto*****
}

RESUMO: O objetivo deste estudo foi desenvolver hedge por meio da combinação de diferentes atividades agropecuárias de modo a oferecer ao produtor rural e usuários em geral, um instrumento para mitigação do risco no mercado agropecuário. Tal instrumento se refere a uma tabela com diferentes portfólios compostos por diferentes atividades agropecuárias, acompanhados de seu risco e retorno operacional mensal, além das alocações ótimas dos recursos financeiros e da área da propriedade rural para cada atividade. Para alcance do objetivo da pesquisa, foi utilizada a teoria do Portfólio de Harry Markowitz (1952) com a elaboração da matriz de correlação entre os retornos das atividades em estudo e o modelo de programação linear, que possui como função objetivo a equação que visa minimizar o risco de um portfólio proposta pelo mesmo autor. Os resultados oferecem portfólios com a combinação de duas, três, quatro, cinco e seis atividades agropecuárias. Foi possível verificar que o Portfólio 1, composto pelas atividades milho e soja, apresentou maior nível de retorno operacional mensal, 15,70\%, para um risco de $2,79 \%$. O Portfólio 6, formado pelas atividades tomate e bovinocultura de corte, oferece o menor nível de risco quando comparado aos outros portfólios, $0,35 \%$, para um retorno operacional mensal de 3,33\%. A escolha do melhor portfólio é feita pelo usuário levando em consideração o nível de risco que ele está disposto a enfrentar.

PALAVRAS-CHAVE: Portfólios; Diversificação; Programação linear.

\footnotetext{
* Mestre em Agronegócio, docente assistente II do Instituto de Ciências Agrárias da Universidade Federal de Viçosa Campus Florestal (UFV CAF), Brasil. E-mail: karineagronegocio@gmail.com

** Mestre em Agronegócio, docente permanente dos cursos de Administração e de Tecnologia do Instituto de Ensino Superior de Rio Verde (IESRIVER), Brasil.

*** Doutor em Economia da Indústria e da Tecnologia, docente adjunto IV da Escola de Agronomia da Universidade Federal de Goiás (UFG), Brasil.

**** Doutor em Administração, docente adjunto III do Curso de Administração do Campus Pontal da Universidade Federal de Uberlândia (UFU), Brasil.
} 


\title{
HEDGE COMBINED TO AGRICULTURAL AND CATTLE-BREEDING ACTIVITIES
}

\begin{abstract}
Hedge was developed by combining different agricultural and cattlebreeding activities to offer a tool for risk mitigation on the market to the rural producer and clients in general. The tool comprises a table with different portfolios composed of different agricultural and cattle-breeding activities plus their risks and monthly operational return, coupled to the best allocations of financial resources and of rural property area for each activity. Harry Markowitz's portfolio (1952) was employed through a correlation matrix involving an equation that aims at minimizing risk of a portfolio proposed by the author. Results provide portfolios by combining two, three, four, five and six agricultural and cattle-breeding activities. Portfolio 1, comprising maize and soybean activities, provided the best monthly return (15.70\%) for a $2.79 \%$ risk, whereas Portfolio 6, comprising tomato and beef cattle provided the lowest risk level $(0.35 \%)$ when compared to other portfolios for a $3.33 \%$ monthly return. The client chooses the best portfolio when he takes into account the risk level he is liable to face.
\end{abstract}

KEY WORDS: Portfolios; Diversification; Linear planning.

\section{INTRODUÇÃO}

O paradoxo entre o aumento populacional e a quantidade fixa de terras agricultáveis, grande parte degradada, exige pesquisas e mecanismos que contribuam para o aumento da eficiência no uso da terra e para a sustentabilidade ambiental. Segundo a Organisation for Economic Co-operation and Development (2016), o expressivo aumento da demanda mundial por alimentos, causado pelo crescimento da população mundial e da renda das famílias, especialmente nas economias emergentes, além da importância em manter e recuperar os recursos naturais, podem ser considerados alguns dos grandes desafios do planeta.

Segundo a OECD (2011), em 2050 haverá cerca de 9,3 bilhões de pessoas no mundo, ou seja, quando comparada à conjuntura atual, que corresponde a uma população de 7 bilhões de pessoas, haverá um aumento de cerca de $30 \%$.

Frente a este cenário questiona-se: Quem alimentará o mundo? Nos próximos dez anos, a produção de alimentos deverá crescer $20 \%$ a fim de atender a 
demanda mundial. Neste panorama, de acordo com a OECD (2011) espera-se que a contribuição para o aumento desta produção seja de União Europeia (4\%), Austrália (7\%), Estados Unidos e Canadá (15\%), Rússia e China (26\%) e Brasil (40\%).

Meadows et al. (1972) questionaram o que seria necessário para manter o crescimento da economia e da população mundial e descreveram uma lista de componentes que consideram imprescindíveis para esta manutenção como água, metais, florestas e, principalmente, terras agricultáveis. Segundo os autores, se o crescimento da população continuasse exponencial, em um curto espaço de tempo, a demanda por solo seria além do limite possível, ocasionando aumento progressivo do preço dos alimentos, levando muitas pessoas a não conseguirem atender suas necessidades.

Devido ao surgimento de técnicas de produção e tecnologias que permitiram aumentar significativamente a produção agropecuária, pode-se afirmar que, ao contrário do que se esperava em Meadows et al. (1972), houve significativa queda no preço dos alimentos componentes de uma cesta básica. O bom desempenho da atividade agropecuária está intimamente relacionado aos aspectos tecnológicos das cadeias produtivas, porém, a oferta de alimentos pode ser ameaçada caso o produtor rural obtenha prejuízos financeiros, principalmente pelos componentes de incertezas do ambiente agrícola que fazem da atividade agropecuária uma atividade de alto risco (MOREIRA et al., 2011).

Segundo Hardaker et al. (2015), incerteza é um conhecimento imperfeito pelo fato de não se conhecer as variáveis ou não saber o real impacto que cada uma delas pode causar e risco é uma consequência incerta, uma possível exposição a eventos desfavoráveis, porém, diferentemente da incerteza, todas as variáveis de uma situação são conhecidas e se tem a possibilidade de se calcular as probabilidades de cada uma delas ocorrerem. No mercado agropecuário o risco é uma variável que pode ser medida ao referir-se à variabilidade dos retornos associada a uma atividade agropecuária (ABSON et al., 2013).

Para amenizar este risco, o produtor rural pode fazer uso de mecanismos específicos que visam assegurar um resultado financeiro mais seguro como, por exemplo, comercializar seus produtos nos diferentes tipos de mercados (mercado a termo, mercado de opções, mercado futuro), formalizar contratos 
com agroindústrias, contratar o seguro agrícola ou desenvolver hedge por meio da combinação de diferentes atividades agropecuárias, de acordo com o que se propõe nesse estudo.

Neste caso, o termo "bedge" é colocado no sentido amplo da palavra, cujo significado é "proteção", e embasa o objetivo do estudo que é verificar o retorno e o risco de diferentes combinações de atividades agropecuárias. Especificamente espera-se que este instrumento auxilie o produtor na alocação dos recursos disponíveis (terra e capital) conforme as alternativas disponibilizadas.

$\mathrm{O}$ procedimento utilizado neste estudo é bastante difundido no contexto teórico do mercado financeiro e emprega, como princípio básico, a diversificação para redução do risco de uma carteira de investimentos. Trata-se da teoria do Portfólio de Harry Markowitz (1952), que no presente estudo permitirá o desenvolvimento do bedge por meio da combinação de diferentes atividades agropecuárias.

O presente estudo é um importante subsídio no processo de tomada de decisão do produtor rural e outros usuários quanto à aplicação de seus recursos financeiros e possibilita que estes se protejam dos riscos financeiros envolvidos na produção agropecuária ao poderem analisar os diferentes níveis de risco e retorno que envolvem as diferentes combinações de atividades agropecuárias, bem como as proporções de terra e capital empregados.

\section{MATERIAL E MÉTODOS}

A pesquisa foi realizada a partir das seguintes etapas: a) Levantamento das séries temporais de preços de mercado e de custos de produção das atividades agropecuárias; b) Análise estatística preliminar dos dados e eliminação dos ilegítimos (outliers); c) Cálculo dos retornos operacionais esperados; d) Teste de estacionariedade das séries temporais; e) Estimativa das volatilidades históricas; f) Definição das alternativas de produção conjunta; g) Análise de correlação dos retornos operacionais das atividades combinadas; h) Desenvolvimento do modelo de programação linear; i) Estimativa dos riscos e retornos operacionais esperados das alternativas em estudo e, por fim, j) Determinação das fronteiras eficientes. 
A priori, foi realizada a coleta dos dados da pesquisa, são eles: os preços médios mensais recebidos pelo produtor, os custos de produção, os indicadores de produtividade e o ciclo de produção de cada atividade agropecuária (algodão, arroz, boi gordo para corte, feijão, milho, soja, sorgo e tomate).

As séries de preços e custos médios mensais referem-se ao período compreendido entre dezembro de 2008 e maio de 2012, o que atinge 42 observações por atividade, totalizando uma amostra com 336 observações.

A pesquisa foi realizada no Estado de Goiás e, por essa razão, os dados trabalhados foram do próprio Estado. Os preços médios mensais recebidos pelo produtor foram disponibilizados pela Companhia Nacional de Abastecimento (Conab). Os preços médios mensais do arroz, feijão, milho, soja e sorgo foram cotados em reais por saca de $60 \mathrm{~kg}$; enquanto que, os preços do algodão e do boi gordo são cotados em reais por arroba. Já a cotação do preço médio mensal do tomate é dada em reais por tonelada do produto. Estes dados foram convertidos em receita por hectare, de acordo com a produtividade de cada atividade, para cálculo do retorno esperado.

Os custos de produção das atividades agrícolas também foram estimados por hectare, enquanto o custo de produção do boi gordo para corte foi analisado por arroba.

Tais custos foram fornecidos pela Federação da Agricultura e Pecuária de Goiás - FAEG. De acordo com a FAEG (2011), a metodologia de custos utilizada pela instituição considera que a evolução dos custos de produção de cada atividade agropecuária se dá pela variação dos preços dos fatores de produção que envolve cada cultura. As cotações dos preços dos insumos que formam os custos de produção nesta metodologia são obtidas junto a cooperativas agropecuárias e empresas de insumos.

A descrição dos custos de produção disponibilizados pela FAEG é subdividida em etapas que agregam custos que incidem desde o período de implantação da cultura até sua pós-colheita. Os custos são definidos com base nas seguintes etapas: correção do solo, pré-plantio, plantio (semeadura e adubação), tratos culturais (controle fitossanitário), colheita, pós-colheita e despesas financeiras (seguros, juros, impostos e taxas e encargos sociais). 
A descrição dos custos de cada etapa relaciona o insumo utilizado, a quantidade utilizada por hectare e seu preço que, somados, compõem o custo total de produção por hectare.

Fatores indiretos que interferem na produção, como relações trabalhistas no meio rural, seguro agrícola, assistência técnica, juros de financiamento, bem como impostos que incidem sobre a renda agrícola, também compõem o custo total de produção disponibilizado pela FAEG, no entanto, foram considerados no estudo apenas os custos operacionais efetivos (COE) de cada atividade, já que os demais custos, que compõem o custo total, são subjetivos, ou seja, variam de produtor para produtor.

Segundo Lopes e Carvalho (2005), o custo operacional efetivo é a soma dos desembolsos efetivamente realizados na condução da atividade. Na metodologia de cálculo de custos de produção da FAEG, o COE é formado pelo somatório das despesas de custeio do pré-plantio, despesas de plantio, despesas de condução da lavoura, despesas de colheita, despesas de pós-colheita e despesas financeiras. No presente estudo foram excluídas as despesas de pós-colheita e as despesas financeiras.

Todas as séries temporais de preços foram deflacionadas com base no Índice Nacional de Preços ao Consumidor Amplo (IPCA), calculado pelo Instituto Brasileiro de Geografia e Estatística - IBGE e os custos de produção foram corrigidos com base no Índice Geral de Preços - Disponibilidade Interna (IGP - DI), disponibilizado pela Fundação Getúlio Vargas - FGV.

Devido à utilização de custos operacionais para cálculo dos retornos das atividades agropecuárias em estudo, o resultado se refere ao retorno operacional esperado calculado a partir da série histórica de receitas obtidas por hectare por atividade a partir da equação 1 :

$$
h_{i t}=p_{i t} x q_{i t}
$$

em que: $b_{i t}$, é a receita por hectare referente à venda do produto da atividade agropecuária $i$, no período $t ; p_{i t}$ é o preço da saca, arroba ou tonelada do produto da atividade agropecuária $i$, no período $t ; q_{i t}$, é a produtividade, por hectare, da atividade agropecuária $i$, no período $t$. 
A partir do cálculo das receitas obtidas por hectare e dos custos operacionais por hectare, disponibilizados pela FAEG, foram obtidas as séries históricas de retorno operacionais de cada atividade por meio da equação 2 :

$$
R_{i, t=} \ln \left(\frac{h_{i, t}}{c_{i, t-n}}\right)
$$

em que: $R_{i, t}$ é o retorno operacional logarítmico da atividade agropecuária $i$, no período $t ; b_{i, t}$ é a receita por hectare referente à venda do produto da atividade agropecuária $i$, no período $t$; $n$, é o tempo de duração (em meses) do ciclo de produção da atividade agropecuária $i$; $c_{i, t-n,}$ é o custo operacional efetivo por hectare que incide durante o ciclo de produção da atividade agropecuária $i$.

Para avaliar o risco, Markowitz (1952) ressalta que, quando analisado individualmente, o risco é definido como a medida de dispersão de uma dada série, ou seja, é determinado pelo cálculo da variância $\left(\sigma^{2}\right)$ ou do desvio-padrão $(\sigma)$. Desta maneira, o risco de cada atividade foi medido a partir do desvio-padrão da série histórica de seus retornos.

Para comparar os riscos com os retornos de diferentes ativos, tem-se o coeficiente de variação (CV) que é uma medida de dispersão relativa que permite este tipo de análise (Gitman, 2004) (equação 3).

$$
C V=\frac{\sigma_{r}}{R_{p}}
$$

em que: $C V$, é o coeficiente de variação; $\sigma_{r,}$ é o desvio-padrão dos retornos esperados e $R_{p}$ é o retorno do portfólio.

Na sequência, foram definidos, para o teste de estacionariedade das séries temporais de retornos operacionais, os testes da raiz unitária de KwiatkowskiPhillips-Schmidt-Shin (KPSS) e Phillips-Perron (PP). A escolha pelo uso destes testes se explica pelo fato de serem testes que permitem a consecução de resultados robustos no que tange a verificação da estacionariedade. 
Por um lado, Carvalho e Ribeiro (2008) ressaltam que o teste KwiatkowskiPhillips-Schmidt-Shin é um teste que verifica se uma série tem ou não raiz unitária e cuja hipótese nula é de que a ação testada é estacionária, ou seja, não apresenta raiz unitária. Por outro, o teste de Phillips-Perron verifica se uma variável tem uma raiz unitária ao considerar a hipótese nula de que a variável contém uma raiz unitária e a hipótese alternativa de que a variável foi determinada por um processo estacionário.

Seguindo os argumentos de Markowitz (1952), de que o coeficiente de correlação é uma importante variável que compõe a medida do risco total de uma carteira de investimentos, e que é a partir deste elemento que se define se uma combinação de ativos em um portfólio é ou não diversificada, foi estimada a relação linear entre os ativos, que se encontra no intervalo de valores entre $+1 \mathrm{e}-1$.

No presente estudo, a matriz de correlação foi construída a fim de dispor a associação linear entre os retornos operacionais das diversas atividades agropecuárias, de forma que se verificasse como cada atividade se relaciona linearmente com as outras atividades que compõem o portfólio. O coeficiente de correlação utilizado para a análise foi o coeficiente de correlação de Pearson.

Visando atingir o objetivo principal do estudo foi realizada a programação linear que de acordo com Osaki e Batalha (2014) é uma importante ferramenta de auxílio no processo de planejamento e tomada de decisão de um investimento já que permite otimizar a alocação de recursos escassos em diferentes atividades de maneira eficiente.

Conforme Mareth et al. (2010), os modelos matemáticos consideram que todas as informações e variáveis relevantes do problema de tomada de decisão podem ser quantificadas. Assim sendo, o modelo matemático é uma representação do sistema que está sendo estudado.

Genericamente, Prado (2004) afirma que o modelo de Programação Linear é apresentado a partir da função objetivo (4), suas restrições (5), (6) e (7) e sua condição de não negatividade (8), como se tem a seguir:

Maximizar ou Minimizar $Z=c_{1} x_{1}+c_{2} x_{2}+\ldots+c_{n} x_{n}$

Sujeito a:

$$
a_{11} x_{11}+a_{12} x_{12}+\ldots a_{1 n} x_{1 n} \leq(\geq) b_{1}
$$




$$
\begin{aligned}
& a_{21} x_{21}+a_{22} x_{22}+\ldots a_{2 n} x_{2 n} \leq(\geq) b_{2} \\
& a_{m 1} x_{m 1}+a_{m 2} x_{m 2}+\ldots a_{m n} x_{m n} \leq(\geq) b_{m} \\
& x_{1 ;} x_{2} ; x_{n} \geq 0
\end{aligned}
$$

em que: $Z$ é a função objetivo; $a_{i j}(i=1, \ldots, m ; j=1, \ldots, n)$, são coeficientes técnicos; $b_{1}, b_{2}, \ldots, b_{m}$, são termos independentes; $c_{1}, c_{2}, \ldots, c_{n}$ são os coeficientes da função objetivo e $x_{1}, x_{2}, \ldots, x_{n}$ são as variáveis de decisão (condição de não negatividade).

Conforme exposto por Markowitz (1952), o risco é quantificado por uma medida de dispersão dos retornos (desvio-padrão ou variância). Desta forma, o modelo de programação linear permitiu determinar como os recursos disponíveis devem ser alocados na propriedade rural, e teve como função objetivo a equação proposta por Markowitz (1952) que busca minimizar o risco de cada portfólio, seguida de suas restrições, como segue:

Minimizar $\sqrt{\sum_{i=1}^{n} \sum_{j=1}^{n} w_{i} w_{j} \rho\left(r_{i} r_{j}\right) \sigma_{i} \sigma_{j}}$

em que: $n$, é o número de atividades agropecuárias que compõem o portfólio; $w_{i,}$ é a participação (proporção) da atividade agropecuária $i$ no portfólio; $w_{j,}$ é a participação (proporção) da atividade agropecuária $j$ no portfólio; $\left(r_{i}, r_{j}\right)$ é a correlação entre os retornos operacionais das atividades agropecuárias $i$ e $j ; \sigma_{i}$ é o risco individual (desvio-padrão) em relação ao retorno esperado da atividade agropecuária $i$; e $\sigma_{j}$ é o risco individual (desvio-padrão) em relação ao retorno esperado da atividade agropecuária $j$.

$$
\sum_{i=1}^{n} w_{i}=1
$$


Esta restrição assegura que todos os recursos disponíveis sejam utilizados.

$$
R_{p}=\sum_{i=1}^{n} w_{i} r_{i} \geq 0
$$

Esta restrição determina que o retorno operacional do portfólio seja igual à soma das proporções de cada atividade agropecuária, vezes seu retorno médio e que o retorno do portfólio seja positivo.

$$
\begin{aligned}
& w_{i} \geq 0, i=1, \ldots, n \\
& w_{j} \geq 0, j=1, \ldots, n
\end{aligned}
$$

Estas restrições garantem que não exista produção negativa.

$$
\sum_{i=1}^{n} a_{i}=151
$$

em que: $a_{i}$ é a área destinada a atividade $i, \mathrm{i}=1, \ldots, \mathrm{n}$;

Esta restrição garante que toda a área da propriedade rural (151 hectares) seja utilizada pela produção conjunta das atividades agropecuárias. O tamanho daárea da propriedade rural se define a partir do Censo Agropecuário de 2006 do Instituto Brasileiro de Geografia e Estatística (IBGE). Neste, a área média das propriedades rurais do Estado de Goiás é de 189 hectares. Destes, 20\% são destinados à reserva legal da propriedade, ou seja, 38 hectares, o restante, 151 hectares, se destina à produção agropecuária.

$$
a_{i} \geq C_{i}, i=1, \ldots, n
$$

em que: $C_{i}$, é a área mínima economicamente viável para a atividade agropecuária $i$. 
A área mínima economicamente viável é a área mínima que cada atividade agropecuária deve ocupar na propriedade para que haja um equilíbrio entre receita e custos totais incorridos na atividade. A área mínima economicamente viável foi obtida por meio da equação:

$$
C_{i}=\frac{P E}{p}
$$

em que: $C_{i}$ é a área mínima economicamente viável; $P E$ é o ponto de equilíbrio em volume; e $p$ é a produtividade. O PE é o nível de produção em que as receitas recebidas igualam-se aos gastos incorridos. Este ponto representa o volume de produção em que o produtor rural não realiza lucro nem prejuízo com a atividade rural. Suas receitas cobrem seus custos de produção, porém o produtor rural só vai obter lucro a partir deste ponto (SANTOS et al., 2002).

De acordo com Santos et al. (2002), o PE pode ser calculado por meio da equação:

$$
P E_{\text {vol }}=\frac{C F_{t o t a l}}{P V_{u n-}-C V_{u n}}
$$

em que: $P E_{v o l}$ é o ponto de equilíbrio em volume; $C F_{\text {total }}$, é custo fixo por hectare; $P V_{u n}$ é o preço de venda unitário (saca, arroba ou tonelada); e $C V_{u n}$ é o custo variável unitário (saca, arroba ou tonelada).

A partir do cálculo dos pontos de equilíbrio das atividades em estudo, as áreas mínimas economicamente viáveis são: algodão (15 hectares), arroz (42 hectares), bovinocultura de corte (11 hectares), feijão (7 hectares), milho (68 hectares), soja (11 hectares), sorgo ( 43 hectares) e tomate ( 40 hectares).

Conforme o objetivo proposto no estudo, a programação linear atuou como importante ferramenta para estimar a alocação dos recursos financeiros e a distribuição da área total da propriedade rural entre as atividades mediante uma 
série de restrições como tamanho da propriedade, capital disponível, área mínima economicamente viável, entre outros.

Entre os procedimentos essenciais para se atingir o propósito da pesquisa, foi realizado o cálculo do retorno operacional de cada atividade a partir das séries históricas mensais de receitas recebidas pelo produtor e dos custos operacionais, ambos calculados por hectare. Para avaliar a série de retornos operacionais de cada atividade agropecuária, obtido ao final de seu ciclo produtivo, foi utilizada a equação 9.

$$
R_{i, t}=\ln \left(\frac{h_{i, t}}{c_{i, t-n}}\right)
$$

em que: $R_{i, t}$ é o retorno operacional logarítmico da atividade agropecuária $i$, no período $t ; b_{i, t}$, é a receita por hectare referente a venda do produto da atividade agropecuária $i$, no período $t ; n$, é o tempo de duração (em meses) do ciclo de produção da atividade agropecuária $i$ e $c_{i, t-n,}$ é o custo operacional efetivo por hectare que incide durante o ciclo de produção da atividade agropecuária $i$.

Com a finalidade de se obter a série de retornos operacionais médios mensais, foram calculados os retornos operacionais equivalentes ao mês, ou seja, as taxas de retorno foram descapitalizadas de acordo com o período do ciclo de produção de cada atividade agropecuária por meio da equação 10 :

$$
R_{i, c}=\sqrt[t]{1+R_{i, t}}-1
$$

em que: $R_{i, c}$, é a taxa de retorno operacional equivalente ao mês da atividade agropecuária $i$, no mês c; $t$, é o ciclo de produção da atividade agropecuária $i ; R_{t, i}$ é o retorno operacional logarítmico da atividade agropecuária $i$, no período $t$.

Posteriormente, foi calculado o retorno operacional médio de cada série histórica de retornos operacionais de cada atividade agropecuária em estudo. A equação 11 foi a base de cálculo deste indicador. 
$R_{m e}=\frac{\sum_{i=1}^{n} R_{i, c}}{n}$

em que: $R_{m e}$ é o retorno operacional médio de cada atividade agropecuária em estudo; $R_{i}$, c, é a taxa de retorno operacional equivalente ao mês da atividade agropecuária $i$, no mês c; e n, é o número de observações de cada série histórica.

O risco de cada atividade agropecuária foi medido pelo desvio-padrão $(\sigma)$ de sua série histórica de retornos operacionais. O Coeficiente de Variação (CV) de cada atividade agropecuária foi calculado pela razão entre o desvio-padrão $(\sigma)$ e 0 retorno operacional médio de cada atividade $\left(R_{m e}\right)$ conforme expresso na equação 12:

$$
C V=\frac{\sigma}{R_{m e}}
$$

\section{RESULTADOS E DISCUSSÕES}

\subsection{ESTATÍSTICAS DE RISCO E RETORNO DAS ATIVIDADES AGROPECUÁRIAS}

A apresentação dos dados e resultados da pesquisa tem início com a exposição dos retornos médios, riscos e coeficientes de variação das atividades em estudo conforme pode ser visualizado na Tabela 1 . Como se pode observar, quanto ao retorno operacional, as atividades que merecem destaque são o milho, o sorgo e a soja, ambos com mais de $15 \%$ de retorno. Por outro lado, o arroz e a bovinocultura de corte foram as atividades agrícolas que apresentaram menores taxas de retorno, mais precisamente, abaixo de $3 \%$. As demais culturas encontram-se no intervalo de retorno entre $5 \%$ e $12 \%$.

No que tange ao risco, foram três atividades com o menor nível de retorno que apresentaram menor volatilidade, são elas, a bovinocultura de corte com 0,33\%, o tomate com 1,61\% e o arroz com 2,73\%. Porém, vale ressaltar que a soja e o milho, que se destacaram em termos de retorno, apresentaram-se bastante equilibrados quando comparados às demais culturas quanto ao risco da atividade, apresentando- 
se em torno de 3,5\% aproximadamente, neste quesito. A cultura do algodão também apresentou risco muito próximo ao do milho e da soja, porém, o sorgo e feijão foram as culturas com maior grau de risco estimado entre as culturas em estudo, ambas em torno de 6,5\% de risco.

Como se pode observar, o milho, a soja e o sorgo, para o período analisado, apresentaram os maiores níveis de retorno operacional. Tais retornos permitem justificar o bom desempenho destas cadeias produtivas, tanto no âmbito regional como no nacional.

Tabela 1. Retornos médios mensais, riscos e coeficientes de variação das atividades agropecuárias

\begin{tabular}{lccc}
\hline \multirow{2}{*}{ Atividades } & Retorno operacional & Risco $(\sigma)$ & Coeficiente de variação \\
\cline { 2 - 4 } & $(\%)$ & $(\%)$ & $(\%)$ \\
\hline Algodão & 10,14 & 3,47 & 34,24 \\
Arroz & 2,69 & 2,73 & 101,62 \\
Bovinocultura de corte & 2,63 & 0,33 & 12,42 \\
Feijão & 11,44 & 6,8 & 59,41 \\
Milho & 16,70 & 3,23 & 19,34 \\
Soja & 15,14 & 2,85 & 18,84 \\
Sorgo & 15,67 & 6,41 & 40,87 \\
Tomate & 5,94 & 1,61 & 27,06 \\
\hline
\end{tabular}

Fonte: Resultados da pesquisa.

Seguindo os procedimentos metodológicos propostos para consecução dos objetivos da pesquisa, foram testadas as séries temporais quanto à estacionariedade com uso dos testes de KPSS e Phillips-Perron.

De acordo com os resultados para o teste KPSS apresentados na Tabela 2, observou-se que as séries de retornos em nível com intercepto mostraram ser estacionárias em todos os níveis de significância, com valores da estatística de Durbin-Watson apresentando valores próximos a 2,0 em todas as séries e sugerindo que as séries não apresentam problemas de autocorrelação residual. 
Tabela 2. Teste da raiz unitária KPSS para as séries de retornos das atividades agropecuárias

\begin{tabular}{|c|c|c|c|c|c|c|}
\hline \multirow{2}{*}{ Atividades } & \multirow{2}{*}{ Teste KPSS } & \multicolumn{3}{|c|}{ Valores críticos } & \multirow{2}{*}{ Durbin-Watson } & \multirow{2}{*}{ Resultado } \\
\hline & & $1 \%$ & $5 \%$ & $10 \%$ & & \\
\hline Algodão & 0.122431 & 0.739000 & 0.463000 & 0.347000 & 1.903 .117 & Estacionária \\
\hline Arroz & 0.409969 & 0.739000 & 0.463000 & 0.347000 & 2.148 .723 & Estacionária \\
\hline Bovinocultura & 0.203651 & 0.739000 & 0.463000 & 0.347000 & 2.144 .090 & Estacionária \\
\hline Feijão & 0.120576 & 0.739000 & 0.463000 & 0.347000 & 2.038 .443 & Estacionária \\
\hline Milho & 0.332149 & 0.739000 & 0.463000 & 0.347000 & 2.034 .401 & Estacionária \\
\hline Soja & 0.156856 & 0.739000 & 0.463000 & 0.347000 & 2.161 .651 & Estacionária \\
\hline Sorgo & 0.073410 & 0.739000 & 0.463000 & 0.347000 & 2.115 .228 & Estacionária \\
\hline Tomate & 0.115898 & 0.739000 & 0.463000 & 0.347000 & 1.983 .565 & Estacionária \\
\hline
\end{tabular}

Fonte: Resultados da pesquisa.

Na Tabela 3 é apresentado o resultado dos testes de raiz unitária de PhillipsPerron, propostos para complementariedade da análise de estacionariedade das séries. Pode-se observar que o valor da estatística do teste é superior aos valores críticos, ou seja, as séries em análise são estacionárias. Assim como no teste KPSS, os valores da estatística de Durbin-Watson do teste de Phillips-Perron sugerem que as séries não apresentam problemas de autocorrelação residual.

Tabela 3. Teste da raiz unitária de Phillips-Perron para as séries de retornos das atividades agropecuárias

\begin{tabular}{|c|c|c|c|c|c|c|}
\hline \multirow{2}{*}{ Atividades } & \multirow{2}{*}{ Teste PP } & \multicolumn{3}{|c|}{ Valores críticos } & \multirow{2}{*}{$\begin{array}{l}\text { Durbin- } \\
\text { Watson }\end{array}$} & \multirow{2}{*}{ Resultado } \\
\hline & & $1 \%$ & $5 \%$ & $10 \%$ & & \\
\hline Algodão & -4.617 .237 & 3.752 .946 & 2.998 .064 & 2.638 .752 & 1.978 .629 & Estacionária \\
\hline Arroz & -9.522 .026 & 3.752 .946 & 2.998 .064 & 2.638 .752 & 2.072 .364 & Estacionária \\
\hline Bovinocultura & -4.975 .089 & 3.752 .946 & 2.998 .064 & 2.638 .752 & 2.004 .290 & Estacionária \\
\hline Feijão & -4.749 .200 & 3.752 .946 & 2.998 .064 & 2.638 .752 & 1.935 .397 & Estacionária \\
\hline Milho & -4.667 .007 & 3.752 .946 & 2.998 .064 & 2.638 .752 & 1.926 .423 & Estacionária \\
\hline Soja & -5.006 .802 & 3.752 .946 & 2.998 .064 & 2.638 .752 & 1.924 .683 & Estacionária \\
\hline Sorgo & -4.971 .146 & 3.752 .946 & 2.998 .064 & 2.638 .752 & 1.923 .071 & Estacionária \\
\hline Tomate & -4.548 .481 & 3.752 .946 & 2.998 .064 & 2.638 .752 & 1.998 .506 & Estacionária \\
\hline
\end{tabular}

Fonte: Resultados da pesquisa. 
Ao considerar a importância da verificação da relação de linearidade entre os retornos das atividades em estudo, na Tabela 4 são apresentados os coeficientes de correlação de Pearson entre os retornos operacionais das atividades em estudo.

A definição quanto à relação de linearidade entre as séries de retorno segue o exposto por Figueiredo Filho e Silva Júnior (2009) que informam que entre 0,00 e 0,30 , a correlação entre as duas variáveis é considerada fraca, enquanto que, o intervalo entre 0,30 e 0,70 indica correlação moderada. Porém, entre 0,70 até 1,00, considera-se a existência de uma forte correlação entre as variáveis.

De acordo com essa classificação, a partir da Tabela 4, é possível verificar que as atividades que apresentam: (a) correlação positiva fraca são algodão e arroz, algodão e tomate, arroz e feijão, arroz e sorgo, bovinocultura de corte e soja, feijão e soja, sorgo e soja e soja e tomate; (b) correlação negativa fraca, arroz e milho, arroz e soja, arroz e tomate, milho e tomate.

As atividades que apresentaram: (a) correlação positiva moderada entre os retornos são algodão e soja, arroz e bovinocultura de corte, milho e bovinocultura de corte, feijão e tomate e milho e sorgo; (b) correlação negativa moderada entre os retornos são algodão e feijão, bovinocultura de corte e feijão, tomate e bovinocultura de corte, feijão e milho, sorgo e tomate.

Verifica-se também que as atividades algodão e bovinocultura de corte, milho e algodão, sorgo e algodão, bovinocultura de corte e sorgo e milho e soja apresentaram correlação positiva forte entre os retornos, enquanto que, apenas o feijão e o sorgo apresentaram correlação negativa forte entre os mesmos.

Tabela 4. Correlação entre os retornos das atividades agropecuárias

\begin{tabular}{lcccccccc}
\hline \multicolumn{1}{c}{ Atividades } & Algodão & Arroz & Bovinocultura & Feijão & Milho & Soja & Sorgo & Tomate \\
\hline Algodão & 1 & 0,285 & 0,791 & $-0,581$ & 0,616 & 0,426 & 0,761 & 0,066 \\
Arroz & & 1 & 0,478 & $-0,086$ & $-0,157$ & $-0,159$ & 0,116 & $-0,142$ \\
Bovinocultura & & & 1 & $-0,636$ & 0,585 & 0,261 & 0,861 & $-0,371$ \\
Feijão & & & & 1 & $-0,410$ & 0,023 & $-0,763$ & 0,505 \\
Milho & & & & & 1 & 0,734 & 0,686 & $-0,147$ \\
Soja & & & & & & 1 & 0,270 & 0,211 \\
Sorgo & & & & & & & 1 & $-0,342$ \\
Tomate & & & & & & & & 1 \\
\hline
\end{tabular}

Fonte: Resultados da pesquisa. 


\subsection{PORTFÓLIOS SELECIONADOS: COMPOSIÇÃO E ALOCAÇÃO DOS RECURSOS}

A análise do retorno e risco dos portfólios (P) tem continuidade com a apresentação da Tabela 5. A disposição da combinação de atividades que melhor atende a perspectiva esperada de risco e retorno contribui para decisão quanto à alocação de recursos financeiros disponíveis e a área da propriedade rural que devem ser distribuídas entre as atividades agropecuárias que compõem o portfólio.

A partir da Tabela 5, o investidor pode analisar 15 portfólios. Sete formados por duas atividades agropecuárias, quatro compostos por três atividades agropecuárias, dois combinados com quatro atividades agropecuárias, um composto por cinco atividades agropecuárias e um composto por seis atividades agropecuárias.

Tabela 5. Composição dos portfólios selecionados

(Continua)

\begin{tabular}{|c|c|c|c|c|c|c|c|}
\hline $\begin{array}{l}\mathrm{N}^{\circ} \text { de } \\
\text { ativ's do } \\
\text { Portfólio }\end{array}$ & \multicolumn{2}{|c|}{ Composição dos portfólios } & $\begin{array}{c}\text { Capital } \\
(\%)\end{array}$ & $\begin{array}{c}\text { Área } \\
(\%)\end{array}$ & $\begin{array}{c}\text { Risco } \\
(\sigma)\end{array}$ & $\begin{array}{c}\text { Retorno } \\
\text { operacional } \\
\text { esperado }\end{array}$ & $\mathrm{CV}(\%)$ \\
\hline \multirow{14}{*}{ 苞 } & Portfólio & Milho & 41,97 & 35,98 & \multirow{2}{*}{$2,79 \%$} & \multirow{2}{*}{$15,70 \%$} & \multirow{2}{*}{$17,79 \%$} \\
\hline & 1 & Soja & 58,03 & 64,02 & & & \\
\hline & \multirow{2}{*}{$\begin{array}{c}\text { Portfólio } \\
2 \\
\end{array}$} & Soja & 89,06 & 77,25 & \multirow{2}{*}{$2,95 \%$} & \multirow{2}{*}{$15,26 \%$} & \multirow{2}{*}{$19,35 \%$} \\
\hline & & Sorgo & 10,94 & 22,75 & & & \\
\hline & \multirow{2}{*}{$\begin{array}{c}\text { Portfólio } \\
3 \\
\end{array}$} & Feijão & 83,52 & 48,32 & \multirow{2}{*}{$2,27 \%$} & \multirow{2}{*}{$13,63 \%$} & \multirow{2}{*}{$16,66 \%$} \\
\hline & & Sorgo & 16,48 & 51,68 & & & \\
\hline & \multirow{2}{*}{$\begin{array}{c}\text { Portfólio } \\
4 \\
\end{array}$} & Arroz & 55,80 & 57,18 & \multirow{2}{*}{$1,92 \%$} & \multirow{2}{*}{$8,69 \%$} & \multirow{2}{*}{$22,06 \%$} \\
\hline & & Milho & 44,20 & 42,82 & & & \\
\hline & \multirow{2}{*}{$\begin{array}{c}\text { Portfólio } \\
5\end{array}$} & Feijão & 1,27 & 3,70 & \multirow{2}{*}{$1,69 \%$} & \multirow{2}{*}{$6,15 \%$} & \multirow{2}{*}{$27,49 \%$} \\
\hline & & Tomate & 98,73 & 96,30 & & & \\
\hline & \multirow{2}{*}{$\begin{array}{c}\text { Portfólio } \\
6\end{array}$} & Tomate & 57,90 & 78,84 & \multirow[b]{2}{*}{$0,34 \%$} & \multirow[b]{2}{*}{$3,33 \%$} & \multirow[b]{2}{*}{$10,27 \%$} \\
\hline & & $\begin{array}{l}\text { Bovinocultura } \\
\text { de corte }\end{array}$ & 42,10 & 21,16 & & & \\
\hline & \multirow[b]{2}{*}{$\begin{array}{c}\text { Portfólio } \\
7\end{array}$} & Algodão & 10,14 & 7,94 & \multirow[b]{2}{*}{$0,55 \%$} & \multirow[b]{2}{*}{$3,22 \%$} & \multirow[b]{2}{*}{$16,91 \%$} \\
\hline & & $\begin{array}{l}\text { Bovinocultura } \\
\text { de corte }\end{array}$ & 89,86 & 92,06 & & & \\
\hline
\end{tabular}


(Continua)

\begin{tabular}{|c|c|c|c|c|c|c|c|}
\hline $\begin{array}{l}\mathrm{N}^{\mathrm{o}} \mathrm{de} \\
\text { ativ's do } \\
\text { Portfólio }\end{array}$ & \multicolumn{2}{|c|}{ Composição dos portfólios } & $\begin{array}{c}\text { Capital } \\
(\%)\end{array}$ & $\begin{array}{c}\text { Área } \\
(\%)\end{array}$ & $\begin{array}{l}\text { Risco } \\
(\sigma)\end{array}$ & $\begin{array}{c}\text { Retorno } \\
\text { operacional } \\
\text { esperado }\end{array}$ & CV (\%) \\
\hline \multirow{12}{*}{ 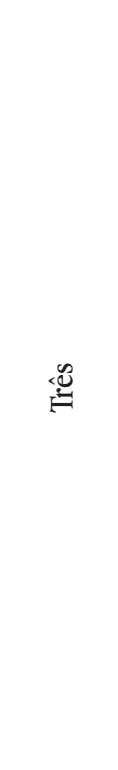 } & \multirow{3}{*}{$\begin{array}{c}\text { Portfólio } \\
8\end{array}$} & Algodão & 39,89 & 18,69 & \multirow{3}{*}{$2,70 \%$} & \multirow{3}{*}{$14,77 \%$} & \multirow{3}{*}{$18,29 \%$} \\
\hline & & Milho & 30,37 & 35,98 & & & \\
\hline & & Soja & 29,74 & 45,33 & & & \\
\hline & Portfólio & $\begin{array}{l}\text { Bovinocultura } \\
\text { de corte }\end{array}$ & 73,52 & 58,20 & & & \\
\hline & 9 & Milho & 23,52 & 35,98 & $1,40 \%$ & $8,42 \%$ & $10,68 \%$ \\
\hline & & Soja & 2,96 & 5,82 & & & \\
\hline & & Sorgo & 5,31 & 22,75 & & & \\
\hline & Portfólio & Soja & 8,58 & 15,33 & $1,70 \%$ & $7,51 \%$ & $22,60 \%$ \\
\hline & & $\begin{array}{l}\text { Bovinocultura } \\
\text { de corte }\end{array}$ & 86,12 & 61,92 & & & \\
\hline & & Milho & 29,23 & 35,98 & & & \\
\hline & Portfólio & Sorgo & 5,99 & 22,75 & $0,82 \%$ & $3,70 \%$ & $22,05 \%$ \\
\hline & & $\begin{array}{l}\text { Bovinocultura } \\
\text { de corte }\end{array}$ & 64,78 & 41,27 & & & \\
\hline & & Tomate & 79,48 & 35,45 & & & \\
\hline & Portfólio & Sorgo & 3,16 & 22,75 & ( & $12=r($ & 16600 \\
\hline & 12 & Milho & 15,42 & 35,98 & & & \\
\hline & & Soja & 1,94 & 5,82 & & & \\
\hline 䓌 & & Arroz & 16,04 & 22,22 & & & \\
\hline & & Milho & 27,46 & 35,98 & & & \\
\hline & $\begin{array}{c}13 \\
\text { POrtIollo }\end{array}$ & Soja & 3,45 & 5,82 & $1,42 \%$ & $8,43 \%$ & $16,88 \%$ \\
\hline & & $\begin{array}{l}\text { Bovinocultura } \\
\text { de corte }\end{array}$ & 53,05 & 35,98 & & & \\
\hline & & Arroz & 16,23 & 22,22 & & & \\
\hline & & Milho & 27,80 & 35,98 & & & \\
\hline O্ב & Portfólio & Soja & 3,49 & 5,82 & $127 \%$ & $923 \%$ & $1381 \%$ \\
\hline ت & 14 & Feijão & 12,27 & 9,04 & & & \\
\hline & & $\begin{array}{l}\text { Bovinocultura } \\
\text { de corte }\end{array}$ & 40,20 & 26,93 & & & \\
\hline
\end{tabular}


(Conclusão)

\begin{tabular}{|c|c|c|c|c|c|c|c|}
\hline $\begin{array}{l}\mathrm{N}^{\circ} \text { de } \\
\text { ativ's do } \\
\text { Portfólio }\end{array}$ & Composiç & o dos portfólios & $\begin{array}{l}\text { Capital } \\
(\%)\end{array}$ & $\begin{array}{l}\text { Área } \\
(\%)\end{array}$ & $\begin{array}{l}\text { Risco } \\
(\sigma)\end{array}$ & $\begin{array}{c}\text { Retorno } \\
\text { operacional } \\
\text { esperado }\end{array}$ & $\mathrm{CV}(\%)$ \\
\hline \multirow{6}{*}{ 胥 } & \multirow{6}{*}{$\begin{array}{l}\text { Portfólio } \\
\quad 15\end{array}$} & Arroz & 10,52 & 22,22 & \multirow{6}{*}{$1,29 \%$} & \multirow{6}{*}{$9,66 \%$} & \multirow{6}{*}{$13,35 \%$} \\
\hline & & Milho & 18,01 & 35,98 & & & \\
\hline & & Soja & 2,26 & 5,82 & & & \\
\hline & & Feijão & 5,21 & 5,93 & & & \\
\hline & & Tomate & 55,41 & 21,16 & & & \\
\hline & & $\begin{array}{c}\text { Bovinocultura } \\
\text { de corte }\end{array}$ & 8,59 & 8,89 & & & \\
\hline
\end{tabular}

Fonte: Resultados da pesquisa.

O portfólio 1, composto pelas atividades milho e soja, apresenta um retorno operacional esperado de $15,70 \%$ para um risco de 2,79\%. Este portfólio sugere que o investidor destine $41,97 \%$ do capital investido à cultura do milho e 58,03\% à cultura da soja, bem como 35,98\% da área da propriedade rural à cultura do milho e 64,02\% da área à cultura da soja. Dentre os portfólios com duas atividades, este é o que atinge maior nível de retorno.

Observando-se o portfólio 2, formado pelas atividades soja e sorgo, notase que, para um risco de 2,95\%, tem-se um retorno operacional esperado de $15,26 \%$, com 89,06\% dos recursos financeiros destinados à cultura da soja e 10,94\% destinados à cultura do sorgo. Neste, $77,25 \%$ da área da propriedade devem ser ocupados pela cultura da soja e $2,74 \%$ devem ser ocupados pela segunda atividade que compõe o portfólio.

O portfólio 3, composto por feijão e sorgo, resulta em um retorno operacional esperado de $13,63 \%$ para um risco de $2,27 \%$ e indica que $83,52 \%$ do capital disponível deve ser aplicado à cultura do feijão e 16,48\% deve ser aplicado à cultura do sorgo. Este portfólio recomenda que 48,32\% da área da propriedade sejam utilizadas para produção de feijão e 51,68\% sejam utilizadas para a produção de sorgo.

Para os demais portfólios, tem-se a mesma interpretação quantitativa quanto ao binômio risco-retorno, a distribuição dos recursos financeiros e da área da propriedade rural. 
Ao questionar qual o melhor portfólio para se investir recomenda-se que se escolha o que possui o menor Coeficiente de Variação (CV). Quando se considera somente as variáveis risco ou retorno isoladamente na escolha de um portfólio negligencia-se uma lei financeira importante que estabelece que o mercado remunera o risco assumido quando se detém determinado ativo pelo retorno operacional esperado. Quando se avalia a escolha do investimento pelo CV se considera o trade off risco-retorno. Portanto, o portfólio 6 composto pelas atividades tomate e bovinocultura de corte $(\mathrm{CV}=10,27 \%)$, é o que representa maior equilíbrio do binômio risco-retorno, ou seja, o retorno operacional esperado ameniza o nível de risco.

$O$ portfólio ideal seria aquele que possibilitasse a mais baixa volatilidade e 0 mais alto retorno, entretanto isto não existe. Os ativos de mais baixo risco oferecem os mais baixos níveis de retornos e, ao contrário, os ativos de mais alto risco oferecem os mais altos níveis de retornos. A teoria de Markowitz (1952) defende que o investidor busca, para determinado retorno, escolher o portfólio que apresente o menor risco ou fazendo a análise oposta, busca-se, para determinada volatilidade, escolher o portfólio que oferece maior retorno esperado. Entretanto, a Tabela 5 do presente estudo dá liberdade de escolha para os diferentes perfis de investidores com suas características particulares de aversão ao risco e expectativas de retorno.

\section{CONSIDERAÇÕES FINAIS}

A aplicação da teoria do Portfólio, proposta por Markowitz (1952), exigiu o conhecimento da taxa de retorno esperado para cada uma das atividades agropecuárias a serem inseridas no portfólio, do risco, quantificado pelo desviopadrão, e do comportamento dos retornos operacionais de cada atividade em relação aos retornos operacionais das demais atividades que compõem a combinação (correlação).

Os resultados mostraram que existem várias alternativas de investimentos na agropecuária que se tornam atrativas quando comparada às outras aplicações da economia como a caderneta de poupança, por exemplo, que apresenta ínfimo 
risco, porém o remunera com um retorno mensal pouco significativo. Além disso, o presente estudo viabiliza o processo de tomada de decisão já que oferece a possibilidade de analisar os diferentes níveis de risco e retorno que envolve as diferentes combinações de atividades agropecuárias, bem como as proporções de terra e capital a serem empregados.

Ademais, em um contexto onde se busca a conservação do meio ambiente por meio da manutenção das florestas e pela recuperação de solos degradados, a intensificação na utilização das áreas agricultáveis é uma necessidade. A diversificação com integração de atividades rurais para gerar renda sem comprometer o meio ambiente é uma alternativa para o produtor que pretende se enquadrar nos mais modernos moldes do desenvolvimento econômico-sustentável.

A metodologia utilizada neste estudo é amplamente empregada no mercado financeiro. A presente pesquisa possibilitou aplicá-la no mercado agropecuário, o qual é extremamente específico pelo alto risco e incertezas que o cercam. No entanto, pode-se buscar o aprimoramento da proposta a partir de novos estudos que utilizarem novas atividades agropecuárias, metodologias e modelos.

A partir do fornecimento de dados de propriedades rurais que adotem sistemas de produção conjunta, é possível analisar como estas se comportam frente ao binômio risco-retorno a partir da metodologia desenvolvida. Esta permite a substituição de atividades já existentes ou a incorporação de novos produtos agropecuários, além da inserção de novas restrições de viabilidade técnica e sinergia para a obtenção de novos portfólios. À medida que se tem conhecimento de outros dados eles poderão ser substituídos no modelo de modo a fornecer novos resultados.

A pesquisa se limitou a utilizar apenas a metodologia de apuração de custos da FAEG para cálculo dos retornos operacionais esperados, porém, outros dados de outras instituições de renome como Cepea e Conab podem trazer novos resultados em busca da expansão da aplicabilidade e aprimoramento do modelo.

O presente trabalho utilizou a volatilidade histórica e correlação constantes, porém, sabe-se que estas podem variar ao longo do tempo (correlação e volatilidade condicionais). Estudos futuros podem incorporar os modelos da família GARCH (General Autoregressive Conditional Heterocedasticity) proposto por Bollerslev (1986), os quais permitem caracterizar os efeitos das mudanças de variâncias nas séries temporais financeiras. Neste caso, periodicamente, se executaria a otimização 
do modelo e, conforme o caso se adotaria novas proporções configurando novos portfólios.

O que se conclui a partir deste estudo é que é possível que o agropecuarista se proteja dos riscos financeiros inerentes ao mercado sem recorrer a mecanismos comumente utilizados como o mercado futuro. O produtor rural pode desenvolver proteção (bedge) de modo simples, produzindo diferentes atividades agropecuárias de maneira conjunta de modo a amenizar os efeitos provenientes das oscilações de preços.

\section{REFERÊNCIAS}

ABSON, D. J.; FRASER, E. D.G.; BENTON, T. G. Landscape diversity and the resilience of agricultural returns: a portfolio analysis of land-use patterns and economic returns from lowland agriculture. Agriculture \& food security, v. 2, n. 1, p. 1, 2013.

BOUERSLEV, T. Generalized autoregressive condicional heteroskedasticity. Journal of Econometrics, 1986.

BRASIL. Companhia Nacional de Abastecimento - CONAB. Indicadores da agropecuária. Disponível em: <http://www.conab.gov.br/> Acesso em: 06 mar. 2012.

BRASIL. Instituto Brasileiro de Geografia e Estatística - IBGE. Índices, Preços e Custos. Disponível em: < http://www.ibge.gov.br/home/mapa_site/mapa_site.php\#indicadores > . Acesso em: 19 maio 2012.

CARVALHO, L. F.; RIBEIRO, K.C.S. Teste de previsibilidades de retornos de ações que compõem o IGC. In: SEMEAD, EMPREENDEDORISMO EM ORGANIZAÇÕES, 11., 2008, São Paulo. Anais eletrônicos... Disponível em: < http://www.ead.fea. usp.br/semead/11semead/resultado/an_resumo.asp?cod_trabalho $=555>$. Acesso em: ago. 2012.

FAEG - Federação de Agricultura e Pecuária do Estado de Goiás. Custo de produção. Disponível em: < http://www.faeg.com.br>. Acesso em: 12 jul. 2012.

FGV - Fundação Getúlio Vargas. Índice Geral de Preços (IGP). Disponível em: 
$<$ http://portalibre.fgv.br/main.jsp?lumChannelId=402880811D8E34B9011D92B6B6420E96 > . Acesso em: 20 jan. 2013.

FIGUEIREDO FILHO, D. B.; SILVA JUNIOR, J. A. Desvendando os mistérios do coeficiente de correlação de Pearson (r). Revista Política Hoje, v. 18, n. 1, 2009.

GITMAN, L. J. Princípios de Administração Financeira. 10. ed. São Paulo: Pearson Addison Wesley, 2004. 745 p.

HARDAKER, J. Brian et al. Coping with risk in agriculture: applied decision analysis. CABI, 2015. $4 \mathrm{p}$.

LOPES, M.A.; MAGALHAES, G.P. Análise da rentabilidade da terminação de bovinos de corte em condições de confinamento: um estudo de caso. Arq. Bras. Med. Vet. Zootec., Belo Horizonte, v. 57, n. 3, p. 374-379, june 2005. Disponível $\quad$ em: $\quad<$ http://www.scielo.br/scielo.php?script $=$ sci_arttext\&pi$\mathrm{d}=$ S0102-09352005000300016\&lng $=$ en\&nrm =iso > . Acesso em: 17 fev. 2016.

MARETH, T.; PAIM, E. S. E.; PIENIZ, L. P.; ERTHAL, F. S. Programação linear como ferramenta de apoio a gestão de custos: um estudo de caso em uma indústria de usinagem. In: SIMPÓSIO BRASILEIRO DE PESQUISA OPERACIONAL, 42., 2010, Bento Gonçalves. Anais... Bento Gonçalves: Sobrapo, 2010, p. 1-12.

MARKOWITZ, H. M. Portfolio selection. The Journal of Finance, v.7, n.1, p. 77-91, 1952.

MEADOWS, D. L.; MEADOWS, D. H; RANDERS, J.; BEHRENS, W.W. Os Limites do Crescimento. São Paulo: Perspectiva, 1972.

MOREIRA, V. R.; BARREIROS, R.F.; PROTIL, R. M. Portfolio de produção agropecuária e gestão de riscos de mercado nas cooperativas do agronegócio paranaense. Revista de Administração, São Paulo, v. 46, n. 4, dez. 2011. Disponível em: <http://www. scielo.br/scielo.php?script $=$ sci_arttext\&pid $=S 0080=21072011000400001-\& l a n g$ pt > . Acesso em: 02 maio. 2012. 
OECD - Organisation for Economic Co-operation and Development. Economic, Environmental and Social Statistics. Disponível em: < http://www.oecd.org/> Acesso em: 12 nov. 2011.

OECD - Organisation for Economic Co-operation and Development. Economic, Environmental and Social Statistics. Disponível em: < http://www.oecd.org/newsroom/oecd-and-fao-see-likely-end-to-period-of-high-agricultural-prices-but-call-forvigilance.htm > . Acesso em: 24 ago 2016.

OSAKI, M.; BATALHA, M. O. Optimization model of agricultural production system in grain farms under risk, in Sorriso, Brazil. Agricultural Systems, v. 127, p. 178-188, 2014.

PRADO, D. S. Programação linear. 4. ed. Nova Lima, MG: INDG Tecnologia e serviços, 2004.

SANTOS, G. J.; MARION, J. C.; SEGATTI, S. Administração de custos na agropecuária. 3. ed. São Paulo: Atlas, 2002. 165 p.

Recebido em:11 de abril de 2016 Aceito em: 04 de outubro de 2016 